\title{
Stress-strain and acoustic emission characteristics of cement-based materials used to simulate soft rock with fractures
}

\section{Handong Liu}

North China University of Water Resources and Electric Power

Jingjing Liu ( $D$ 1332824613@qq.com )

North China University of Water Resources and Electric Power

Shiying Zhang

North China University of Water Resources and Electric Power

Lingyun Feng

North China University of Water Resources and Electric Power

Lei Qiu

North China University of Water Resources and Electric Power

\section{Research Article}

Keywords: soft rock-like, uniaxial compression, acoustic emission, fracture angle, fracture connectivity, deformation and failure mode

Posted Date: February 10th, 2022

DOI: https://doi.org/10.21203/rs.3.rs-1328352/v1

License: (c) (i) This work is licensed under a Creative Commons Attribution 4.0 International License. Read Full License 


\section{Stress-strain and acoustic emission characteristics of cement-based}

\section{materials used to simulate soft rock with fractures}

Handong Liu, Jingjing Liu, Shiying Zhang, Lingyun Feng, Lei Qiu

Jingjing Liu, Ph.D. Student, College of Geosciences and Engineering, North China University of Water Resources and Electric Power, Zhengzhou 450046, China

(1332824613@qq.com)

Abstract: Instability failure in rock mass engineering is closely related to the expansion of joint fissures. In this study, uniaxial compression tests and acoustic emission (AE) measurements were simultaneously carried out on soft rock-like material with different angle and connectivity of fractures to better understand their influence on soft rock-like deformation and failure. The stress-strain curve and $A E$ signal of fractured soft rock-like material exhibit similar stages as intact soft rock; namely a compaction stage, elastic deformation stage, stable fracture development stage, and unstable fracture development stage. The main differences occur within the post-peak failure stage. Under the combined influence of fracture angle and connectivity, the uniaxial compressive strength of fractured soft rock-like material $\left(f_{c u}^{\prime}\right)$ is lower than that of the intact soft rocklike material $\left(\mathrm{f}_{\mathrm{cu}}\right)$ to varying degrees and can be described as $\mathrm{f}_{\mathrm{cu}}^{\prime}=\mathrm{f}_{\mathrm{cu}} \cdot \alpha$, where $\alpha$ is the strength reduction coefficient, fitted as $\alpha=0.8228+$ $0.00411 \mathrm{x}-0.00789 \mathrm{y}$. In this equation, $x$ is the fracture angle $\left(^{\circ}\right)$ and $y$ is the fracture connectivity rate (\%). Under uniaxial compression, secondary cracks caused by the deformation and failure of the fractured soft rock-like specimens mainly included wing cracks and secondary coplanar cracks. The specimen with a fracture angle of $30^{\circ}$ mainly underwent tensile failure under loading, whereas 
the specimens with $45^{\circ}$ and $60^{\circ}$ fracture angle mainly underwent shear failure under high-connectivity conditions (45\%).

Keywords: soft rock-like, uniaxial compression, acoustic emission, fracture angle, fracture connectivity, deformation and failure mode

\section{Introduction}

Natural rock mass generally contains a complex distribution of joints, faults, and other structural planes that occur at different scales. The randomness and inhomogeneous distribution of such features cause the rock mechanical properties to exhibit non-linear, inhomogeneous, and anisotropic characteristics, which can lead to high degrees of damage ${ }^{1,2}$. The influence of fractures on rock mass mainly manifests in two ways. The essence of rock mass deformation and failure is ultimately the process of fracture initiation, expansion, and coalescence under engineering disturbance conditions. However, rock mass fracturing also changes the stress state, which further affects the failure form and engineering instability process. Several studies have investigated high-strength rock with different fracture features, such as fracture spacing, connectivity, and angle, and number of fractures ${ }^{3,4} \cdot \mathrm{Hu}^{5}$ found, through analysis of the mechanical parameters of a fractured rock mass, that the joint plane weakens the strength of the rock mass. Under different combinations of joint occurrence and spatial position, the strength of the rock mass exhibited obvious 
and varying degrees of anisotropy. Wang and Xiong ${ }^{6}$ studied the variation of the ultimate strength of a single fractured rock mass by means of uniaxial compression testing and numerical simulation. The ultimate strength showed a negative correlation with fracture length and thickness, and as the fracture angle increased, the ultimate strength decreased initially and subsequently increased. Yin et ${ }^{7}$ discussed the influence of joint inclination on the rock strength and strain path using data on the basic mechanical parameters of rock obtained from uniaxial compression tests. The greatest influence on the strain path was observed for a joint inclination of $90^{\circ}$. The failure mode of the rock mass is closely related to its stress field, and the primary fracture further controls the propagation direction and mode of secondary cracking ${ }^{8}$. In addition to the influence of fracture characteristics (e.g., fracture angle and fracture connectivity.) on the mechanical characteristics of rock mass, the geometric parameters such as fracture group number, continuity, density, and arrangement also have an important influence on the macro mechanical behavior of rock mass. At present, the application of fracture in brittle rock is relatively mature, but the study of soft rock with fracture is not perfect.

The heterogeneity of rock mass itself, the diversity and difference of fracture distribution in rock mass, and the research on the strength, deformation, and failure characteristics of fractured rock mass are more complex. Soft rock mass (e.g., mudstone, shale, siltstone) is widely distributed worldwide ${ }^{9}$. The low strength of soft rock, the weak development of its 
structural plane and even its rheological characteristics not only seriously affect the construction safety and progress of projects, but also increase the economic burden, especially in tunnel, dam, and slope engineering construction. Consequently, the mechanical properties of soft rock have an important influence on the stability of a project ${ }^{10,11}$. To understand the uniaxial compression strength characteristics and penetration mechanism of nonpenetrating fractured soft rock, Wang et ${ }^{12}$ studied the strength characteristics of non-penetrating fractured soft rock under uniaxial compression failure conditions. The research shows that the non-penetrating fractured samples under different fracture characteristics show different failure characteristics, which has important reference value for solving the problems of strength calculation and failure mechanism of fractured rock mass encountered in practical engineering. On the basis of the analysis of creep characteristics of soft rock under uniaxial compression, Fan et ${ }^{13}$ established axial and transverse nonlinear creep models of soft rock by introducing damage variables and hardening function. The existence of cracks makes soft rock produce a series of unique mechanical characteristics, and these characteristics are related to-for example-the genetic type of cracks and crack occurrence. Therefore, a comprehensive understanding of the stability and mechanical properties of fractured soft rock is critical.

Acoustic emission is produced when energy is released in the form of elastic waves upon the microcracks in rock materials under stress conditions. AE 
technology can therefore be used to analyze crack evolution and rock damage mechanisms ${ }^{14}$. Previous studies have shown that different rock types and loading modes (e.g., tensile, splitting, uniaxial compression) produce different AE characteristics, and that the characteristics of crack growth and rock failure mechanisms also differ ${ }^{15,16}$. The AE technology can be used to obtain real-time, transient, or continuous signals to monitor the development and penetration process of internal cracks in rocks, and thus predict the early or recent fracturing of brittle materials caused by external loads ${ }^{17}$.

AE technology has mostly been applied in experimental studies on hard rock with uniaxial compressive strength values greater than $30 \mathrm{MPa}^{18}$. The rock strength, grain hardness, joint fracture characteristics, and other factors will affect the AE characteristics of rock materials. The application of $A E$ technology to soft rock is difficult owing to its characteristics of low strength, high porosity, poor cementation, and considerable sensitivity to structural surface cutting and weathering. There have therefore been a limited number of studies on fractured soft rock using AE. Browning et ${ }^{19}$ investigated soft rock crack damage by monitoring the stress and strain changes in AE signals and concluded that fracture damage only occurs when the stress exceeds a certain threshold. Previous studies on the AE of soft rock mainly focused on practical engineering applications, such as for roadways, coal mines, and tunnel caves ${ }^{20}$, and little attention has been paid to soft rock deformation.

In the present study, uniaxial compression tests were performed to 
investigate the effect of fracture angle (the angle between the fracture and the horizontal direction) and connectivity rate (the ratio of the fracture length to diagonal length of the sample surface) on the soft rock-like mechanical characteristics and failure mode, while simultaneously applying AE monitoring technology to study the fracture initiation, propagation, and penetration processes. The results are used to summarize the stress-strain behavior and $A E$ characteristics of fractured soft rock, and the evolution mechanism of deformation and failure are discussed as a function of fracture angle and connectivity rates.

\section{Test materials and equipment}

Natural fracture-bearing soft rock samples are difficult to obtain; thus, in this study we used cement mortar with mechanical properties (e.g., strength, elastic modulus, and Poisson's ratio) similar to those of soft rock. The cement mortar can exhibit the mechanical properties and acoustic emission characteristics of soft rock. In rock engineering, rock strength and elastic modulus are two important mechanical parameters. Research on mechanical properties of soft rock (Table 1) and rock classification standards indicate that a rock surface with uniaxial compressive strength less than $25 \mathrm{MPa}$ is called soft rock $^{21}$. The material selected for testing should be consistent with the mechanical properties of soft rock (e.g., strength, elastic modulus, and Poisson's ratio), as demonstrated by experimental studies on the soft rock of the dam 
foundation of the Baihetan hydropower station ${ }^{22}$.

Table 1 Mechanical properties of soft rock measured in previous studies

\begin{tabular}{|c|c|c|c|c|}
\hline Reference & Rock type & $\begin{array}{c}\text { Compressive } \\
\text { strength } \\
(\mathrm{MPa})\end{array}$ & $\begin{array}{c}\text { Elastic } \\
\text { Modulus } \\
(\mathrm{GPa})\end{array}$ & $\begin{array}{l}\text { Poisson's } \\
\text { Ratio }\end{array}$ \\
\hline Fan et al. $(2007)^{23}$ & Siltstone & $7 \sim 15$ & 4.85 & \\
\hline Li et al. (2021) ${ }^{24}$ & Siltstone & $6.9 \sim 12.0$ & & \\
\hline \multirow{3}{*}{$\begin{array}{l}\text { Zhou et al. } \\
(2004)^{25}\end{array}$} & Sandstone & $21.39 \sim 39.01$ & $2.4 \sim 3.8$ & $0.15 \sim 0.19$ \\
\hline & Siltstone & $5.50 \sim 17.59$ & $0.6 \sim 1.2$ & $0.17 \sim 0.24$ \\
\hline & Mudstone & $3.49 \sim 10.01$ & $0.62 \sim 0.72$ & $0.15 \sim 0.19$ \\
\hline Zhu et al. $(2019)^{26}$ & Phyllitic slate & $6.9 \sim 25.3$ & $0.8 \sim 1.2$ & $0.32 \sim 0.35$ \\
\hline
\end{tabular}

\subsection{Mortar raw materials}

The raw materials of the cement mortar used in the tests were ordinary Portland cement 42.5 (Table 2), natural river sand (Table 3), and urban tap water, which meet the GB/t14684-2011 standard requirements ${ }^{27}$.

Table 2 Cement properties

\begin{tabular}{llllll}
\hline \multicolumn{2}{c}{ Setting time } & \multicolumn{2}{c}{ Compressive strength } & \multicolumn{2}{c}{ Flexural strength } \\
\hline Initial & Final & 3 days & 28 days & 3 d days & 28 days \\
$175 \min$ & $288 \min$ & $23.3 \mathrm{MPa}$ & $47.2 \mathrm{MPa}$ & $4.7 \mathrm{MPa}$ & $8.6 \mathrm{MPa}$ \\
\hline
\end{tabular}

Table 3 Aggregate properties

\begin{tabular}{ccccc}
\hline Material & $\begin{array}{c}\text { Size } \\
(\mathrm{mm})\end{array}$ & $\begin{array}{c}\text { Apparent density } \\
\left(\mathrm{kg} / \mathrm{m}^{3}\right)\end{array}$ & $\begin{array}{c}\text { Mud content } \\
(\%)\end{array}$ & $\begin{array}{c}\text { Fineness } \\
\text { modulus }\end{array}$ \\
\hline fine & $0 \sim 4.75$ & 2650 & 1.5 & 2.7 \\
aggregates & & & & \\
\hline
\end{tabular}

\subsection{Mortar mix proportion}

Because it is difficult to obtain natural fractured soft rock samples, this paper uses soft-rock-like materials that can reflect the mechanical properties of real fractured soft rock-like material (e.g., strength, elastic modulus, Poisson's 
ratio). In keeping with this principle and combined with the experimental study on the soft rock mass of the dam foundation of the Baihetan hydropower station by Liu ${ }^{22}$, cement, sand, and water were selected as the soft rock preparation materials. A large number of comparative and screening tests were performed to determine the ideal mortar mixture proportion to best represent real fractured soft rock. The results indicate an optimal ratio of cement : sand : water of 1:5:0.9.

\subsection{Specimen preparation}

Prefabricated fractured soft rock-like specimens were prepared using the steel bar method. The mold was spliced by $15-\mathrm{mm}$ steel plates, as shown in Fig. 1. The middle position of the side wall contained a rotatable disc, and the slit was cut in the middle of the disc. The angle of the slit can be adjusted by rotating the disc. Each rotatable disc has a single connectivity. Three rotatable discs were used corresponding to three connectivity values to prepare the fractured soft rock-like samples with different connectivity and angle values.
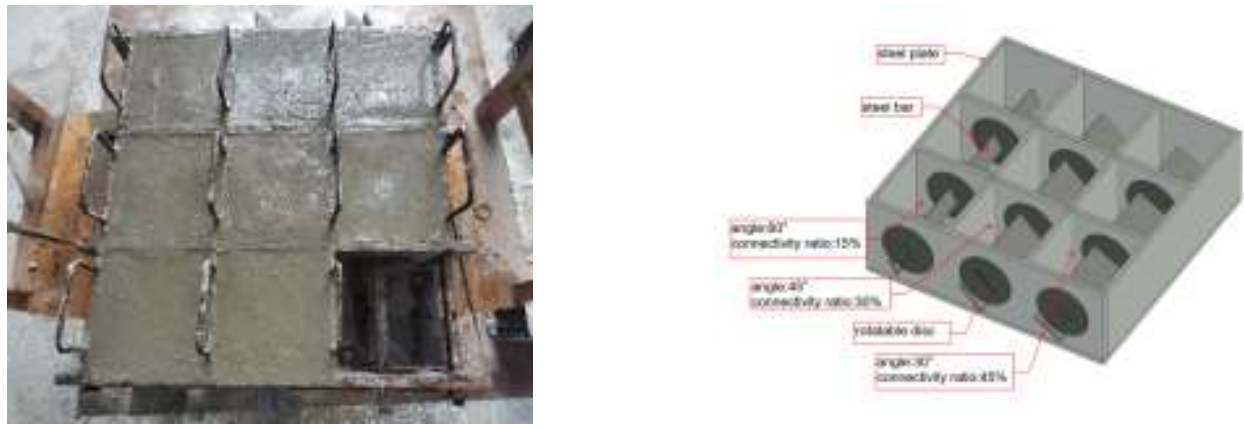

Fig 1 Preparation mold of fractured soft rock-like specimens 
A total of 10 groups of 30 soft rock-like specimens with dimensions of 150 $\times 150 \times 150 \mathrm{~mm}$ were prepared, as shown in Table 4. Group 1 was an intact soft rock-like specimen without fractures, with an elastic modulus of $3.2 \mathrm{GPa}$ and Poisson's ratio of 0.28 . The other nine groups included fractured soft rock-like samples with different combinations of fracture angle and connectivity values. The fracture angle (i.e., the angle between the fracture surface and horizontal direction) of the fracture samples were set to $30^{\circ}, 45^{\circ}$, and $60^{\circ}$, and the fracture connectivity (i.e., the ratio of the fracture length to the diagonal length of the sample surface) was set to $15 \%, 30 \%$, and $45 \%$.

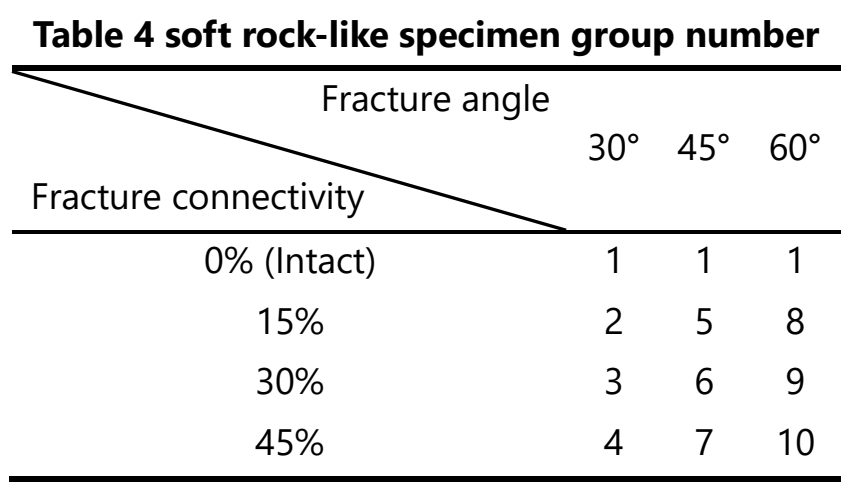

The engine oil was first removed from the combined mold and steel bar, and the angle of the bar was set according to the target fracture angle. The mixed cement mortar was evenly poured into the mold in several small batches. The samples were then manually vibrated to reduce the number of interior bubbles, while carefully avoiding any disturbance to the steel bar. The steel bar was removed prior to the initial mortar setting to obtain the open prefabricated fractured soft rock-like specimen. The specimen was allowed to stand for $24 \mathrm{~h}$ and then placed in a curing room for 28 days. The soft rock-like specimens that met the test standards were then selected, Fig. 2. 

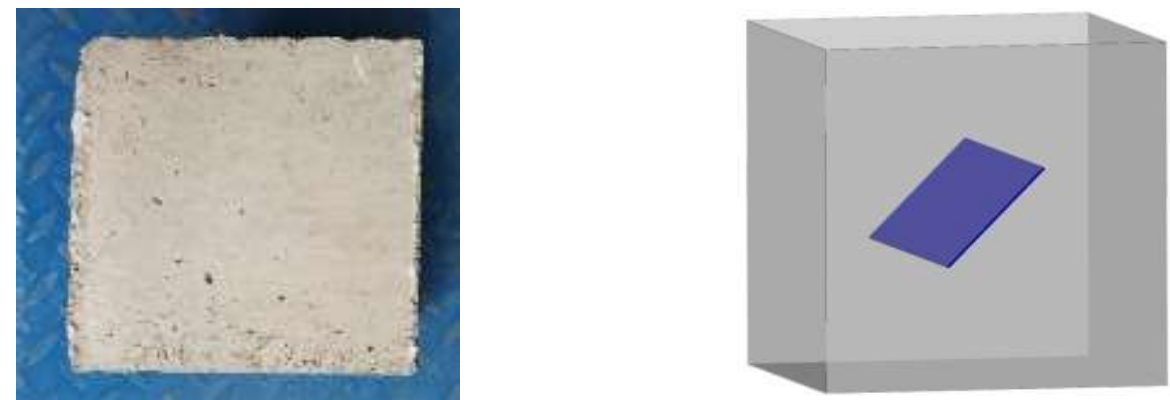

Fig 2 Specimen image of fractured soft rock

\subsection{Test method}

A YAM6206 servo press was used as the pressurizing device for the uniaxial compression tests (Fig. 3), and a $\mathrm{PCI}-\mathrm{II} A E$ device was used to monitor the $\mathrm{AE}$ signal during the specimen compression and failure process, as shown in Fig. 3. The maximum loading capacity of the servo press is $2000 \mathrm{kN}$ and the maximum loading rate is $80 \mathrm{~mm} / \mathrm{min}$. The type of the $A E$ sensor was $\mathrm{R} 6$ with a preamplifier gain of $40 \mathrm{~dB}$ and sampling frequency of $2 \mathrm{MHz}$. Four $\mathrm{AE}$ sensors were coupled to the side of the sample with Vaseline. The threshold voltage was set to 100 $\mathrm{mV}$ to reduce environmental noise according to the test conditions and test environment.

The cubic soft rock-like specimens were placed on the loading platform of the servo press, and an AE probe was fixed to the centers of each of the four sides of the specimen. The AE system started to monitor the data when the pressure system touched the sample surface. The loading rate of the servo press was set to $20 \mathrm{~mm} / \mathrm{min}$. The servo press data acquisition system was used to measure the mechanical properties of the soft rock-like material, and four $\mathrm{AE}$ systems were used to monitor the AE characteristics of the specimen during the 
instability and failure process.

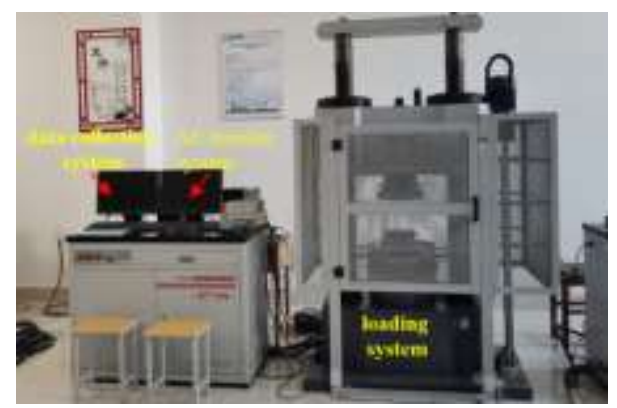

Figure 3 Schematic diagram of the test assembly

\section{Test results and analysis}

Ten groups of soft rock-like specimens were subjected to three uniaxial compression-AE tests under the same conditions to reduce test error. The results of one test were selected for analysis, and the results of the other two tests were used as reference data.

\subsection{Stress-strain curves and acoustic emission characteristics of intact soft rock-like material under uniaxial compression}

\subsubsection{Determination of stress-strain curve characteristic points}

The stress $(\sigma)$-strain $(\varepsilon)$ data of an intact soft rock-like specimen under uniaxial compression were normalized to $\left(\sigma / \sigma_{f}\right)$ and $\left(\varepsilon / \varepsilon_{f}\right)$, where $\sigma f$ represents the peak stress and $\varepsilon_{f}$ represents the strain at the peak strength, as shown in Fig. 4. The stress-strain curve clearly shows differentiated stages on a macro-perspective. The slope of the two adjacent data points $\left(\left(\sigma_{i}, \varepsilon_{i}\right),\left(\sigma_{(i+1)}, \varepsilon_{(i+1)}\right)\right)$ were calculated based on the stress-strain data 
according to Eq. (1), as shown in the curve secant module in Fig. 4:

$$
E_{i}=\frac{\left(\sigma_{i+1}-\sigma_{i}\right)}{\left(\varepsilon_{i+1}-\varepsilon_{i}\right)} \times 10^{-1}(i=1,2,3, \ldots, n)
$$

where $i$ is the serial number of the $\sigma-\varepsilon$ data points.

Figure 4 shows that the secant modulus curve of intact soft rock-like material can be clearly divided into four stages: stable rising stage; horizontal stage; stable declining stage; and accelerated falling stage, which respectively correspond to the $\mathrm{O}-\mathrm{A}, \mathrm{A}-\mathrm{B}, \mathrm{B}-\mathrm{C}$, and $\mathrm{C}-\mathrm{D}$ sections on the stress-strain curve. These stages are referred to as the compaction stage $(\mathrm{O}-\mathrm{A})$, elastic deformation stage $(A-B)$, stable fracture development stage $(B-C)$, and unstable fracture development stage (C-D), respectively.

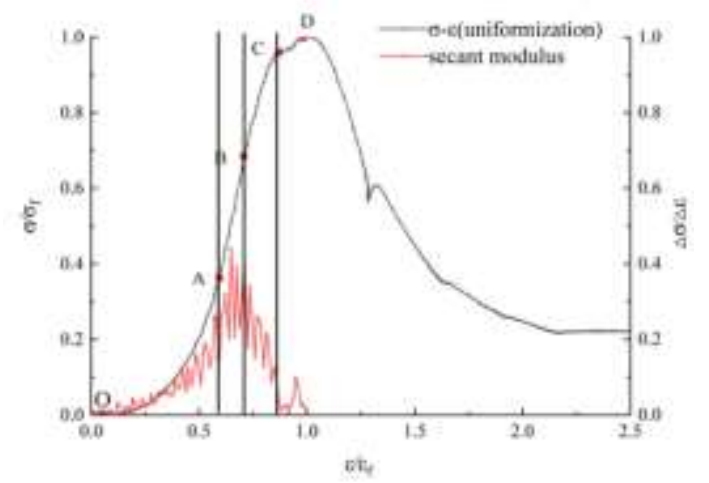

Fig.4 Stress-strain curve of the intact specimen under uniaxial compression and the determination of feature points

\subsubsection{Acoustic emission characteristics of the stress-strain curves}

The failure process of soft rock-like material includes the development process of internal fracture initiation, propagation, and penetration. The $A E$ characteristics are closely related to the failure process and therefore better 
correspond to the failure stage (Fig. 5). The development of internal fractures in different failure stages of soft rock-like material can be further analyzed according to the AE characteristics.

During the initial loading stage $(\mathrm{O}-\mathrm{A})$, the soft rock-like specimen is compressed under an axial compression load, and a small amount of AE energy appeared, which indicates that the internal primary fracture had closed or developed to varying degrees under axial compression.

Upon increased loading (A-B), the specimen showed a small amount of energy release and occasionally generated a small number of micro-fractures, thus entering the stable development stage. The impact of internal damage on the entire specimen remained small, which can be explained by the specimen being accompanied by a small amount of plastic deformation during the elastic deformation stage. Point $A$ in Fig 5 . shows the elastic starting point with a stress of $0.36 \sigma_{f}$, and point $B$ is the elastic limit point with a value of $0.68 \sigma_{f}$.

When loaded to a certain extent $(B-C)$, the plastic deformation of the soft rock-like specimen gradually accelerated, the internal fractures of the specimen generally expanded, the elastic energy accumulated in the specimen was stably released, the $A E$ signal was relatively dense, the released energy was higher, and the specimen produced a large number of unrecoverable plastic deformation features.

As the axial load continued to increase, the AE energy was released and entered the peak period, the specimen released more energy than in the 
previous stages, and the internal fractures entered the unstable propagation stage (C-D). Point $C$ in Fig. 5 represents the development point of the internal main fracture and the stress reaches $0.96 \sigma_{f}$ corresponding to a Poisson's ratio $v_{t}>>0.5^{28}$. When the stress reached point $D$, the internal fractures of the specimen rapidly propagated and passed through the entire specimen along the inclined shear plane $\left(\sim 45^{\circ}\right.$ to the axis).

After the specimen reached its peak strength, a small amount of AE energy was released, indicating that the specimen had low residual stress depending on the bite and friction between the segments.

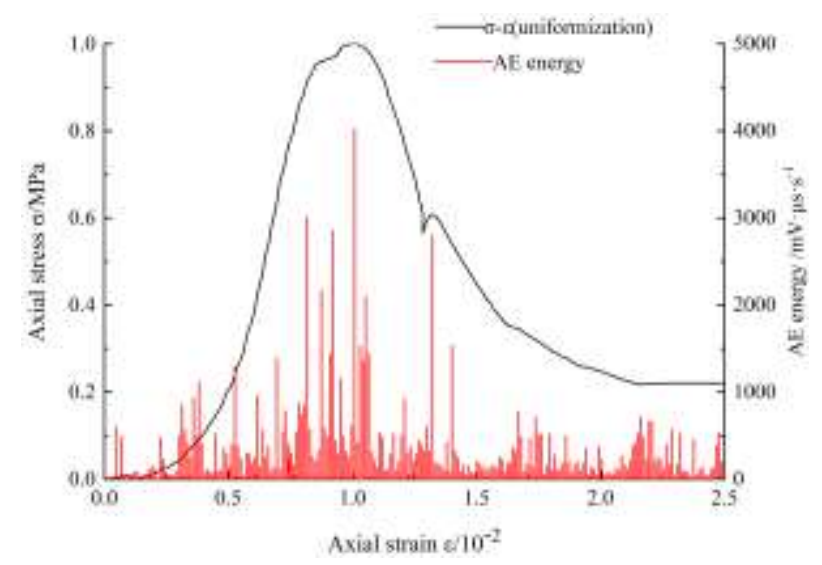

Fig. 5 Acoustic emission energy analysis

In conclusion, the $\mathrm{AE}$ results can reflect the internal energy release process of soft rock-like material and the entire process of microfracture growth, aggregation, and penetration until failure under uniaxial compression. The stress-strain curve of soft rock-like material is thus highly consistent with its $A E$ energy signal. 


\subsection{Stress-strain curve and acoustic emission characteristics of fractured}

\section{Similar- soft rock}

\subsubsection{Effect of fractures on the stress-strain curve and acoustic emission characteristics}

The stress-strain curves of the fractured soft rock-like material are divided into stages according to the method by which the characteristic points are determined (Fig. 6). Prior to reaching the peak strength, the stress-strain curve of the fractured soft rock-like material clearly shows similar stages of change as the intact soft rock. However, owing to the influence of certain conditions, there is a secondary peak phenomenon (Fig. 6a) or trend (Fig. 6b) during the postpeak failure stage of the fractured soft rock.

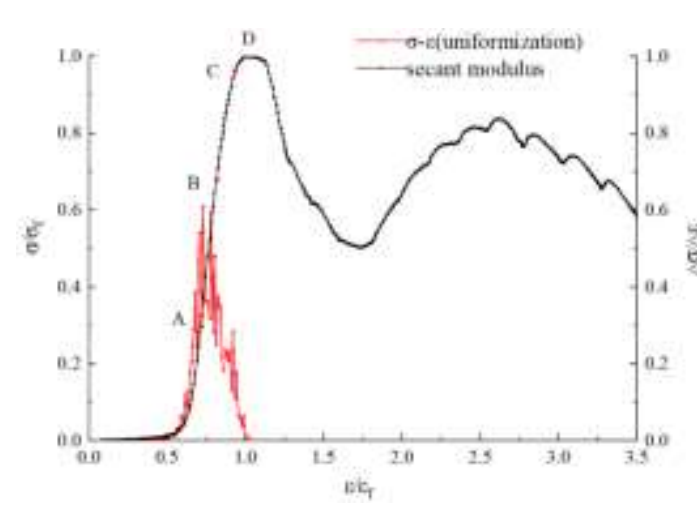

(a) Fracture angle of $60^{\circ}$ and $30 \%$ fracture connectivity
8

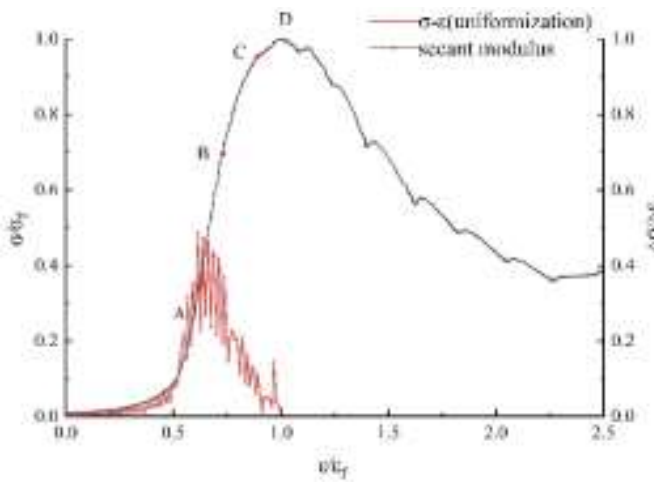

(b) Fracture angle of $60^{\circ}$ and $15 \%$ fracture connectivity

Fig. 6 Stress-strain curve and secant modulus curve of a fractured soft rock-like-like specimen

The stress-strain curves can be divided into three categories according to the uniaxial compression and $A E$ test results on 27 fractured soft rocks. (1) When the fracture connectivity is either small $(15 \%)$ or medium (30\%) and the angle is small $\left(30^{\circ}\right.$ or $\left.45^{\circ}\right)$, or the connectivity is high (45\%) and the angle is 
small $\left(30^{\circ}\right)$, an upward trend is observed in the post-peak failure stage, as shown in Fig. 7a. (2) When the fracture has medium connectivity (30\%) and a large angle $\left(60^{\circ}\right)$, a secondary peak appears in the post-peak failure stage, as shown in Fig. 7b. (3) When the fracture connectivity is large (45\%) and the angle is large $\left(45^{\circ}\right.$ or $\left.60^{\circ}\right)$, there is no secondary peak phenomenon or trend in the post-peak failure stage of fractured soft rock, which is similar to the post-peak failure stage of intact soft rock, as shown in Fig. 7c.

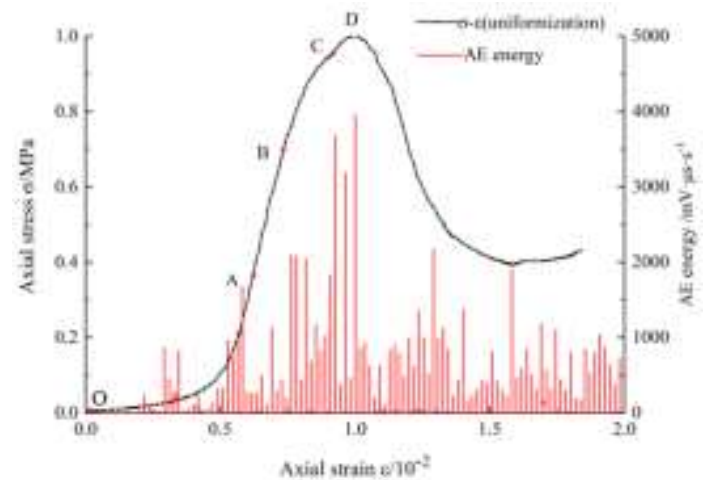

(a) Fracture angle of $30^{\circ}$ and $15 \%$ fracture connectivity

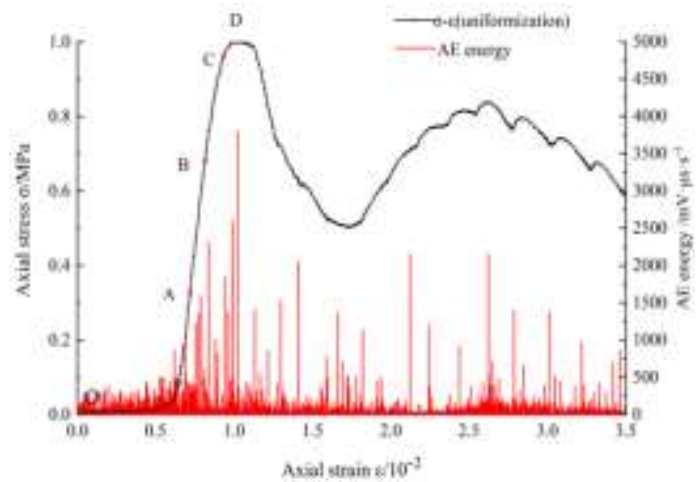

(b) Fracture angle of $60^{\circ}$ and $15 \%$ fracture connectivity

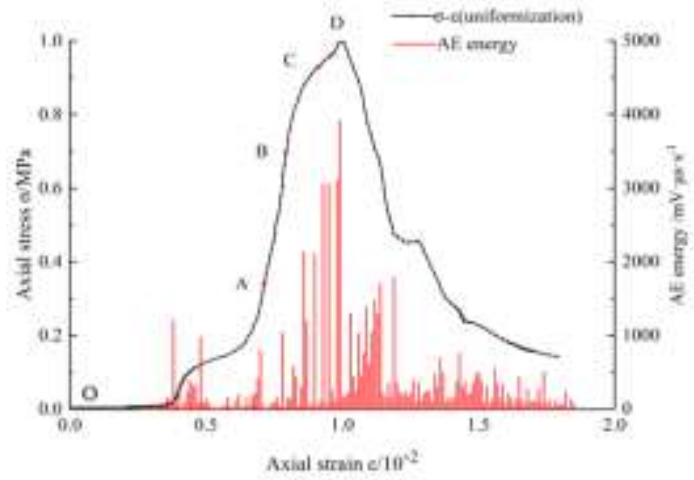

(c) Fracture angle of $45^{\circ}$ and $415 \%$ fracture connectivity

Fig. 7 Stress-strain curves and acoustic emission characteristics of the fractured soft rock-like specimens

In summary, the characteristics of the uniaxial compression stress-strain curves of the 27 fractured soft rock-like specimens also show a compaction stage, elastic deformation stage, stable fracture development stage, and unstable fracture development stage. Their corresponding AE characteristics are 
similar to those of intact soft rocks with differences of only specific values. The stress-strain curves of fractured and intact soft rock-like material substantially differ in the post-peak failure stage.

\subsubsection{Effect of fractures on the peak strength of soft rock}

The peak strength of the intact soft rock-like specimen was $11.95 \mathrm{MPa}$.

Owing to the stress damage effect ${ }^{29}$, the peak strength of the fractured soft rock-like material was lower than that of the intact specimen to varying degrees (Table 5).

Table 5 Peak strength and reduction rate of specimens with different fracture connectivity and

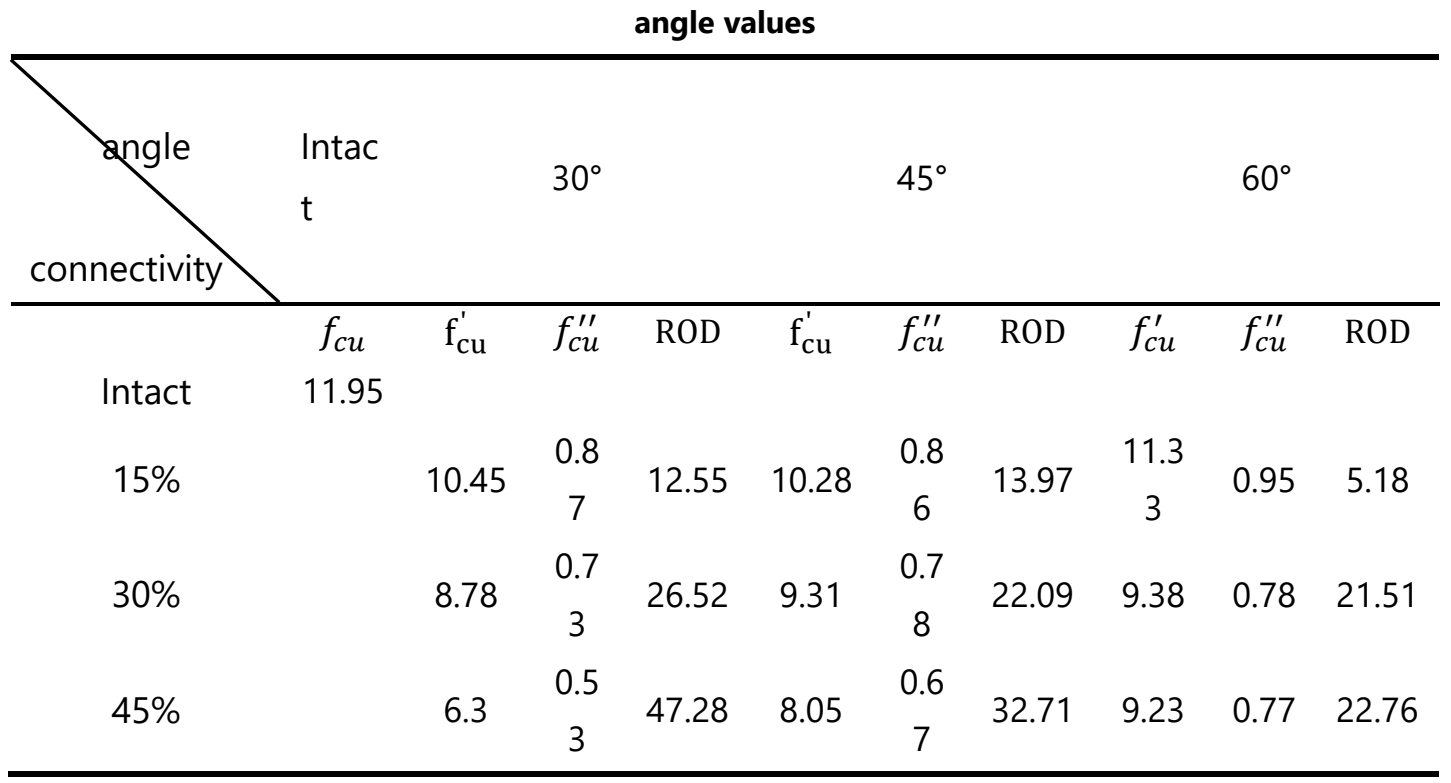

$f_{c u}$ is the peak strength of intact soft rock; $f_{c u}^{\prime}$ is the peak strength of fractured soft rock; $f_{c u}^{\prime \prime}$ is the normalized peak strength of the fractured soft rock; and ROD is the reduction rate of the peak strength.

The peak strength decline rate of the specimen decreases with increasing fracture angle and increases with increasing fracture connectivity. The minimum 
decline was $5.18 \%$ for the specimen with $15 \%$ connectivity and a $60^{\circ}$ fracture angle, and the maximum decline was $47.28 \%$ for the specimen with $45 \%$ connectivity and a $30^{\circ}$ fracture angle, for which the corresponding peak strength is only $6.30 \mathrm{MPa}$, which is approximately half of the peak strength of the intact soft rock.

The variation law of the peak strength of fractured soft rock-like material is analyzed as a function of fracture angle and connectivity, as shown in Fig. 8. When the fracture connectivity is held constant (e.g., 15\%, 30\%, 45\%), the peak strength of the fractured soft rock-like material essentially increases with increasing fracture angle. When the fracture angle is held constant (e.g., $30^{\circ}$, $\left.45^{\circ}, 60^{\circ}\right)$, the peak strength of the fractured soft rock-like specimens decreases with increasing fracture connectivity.
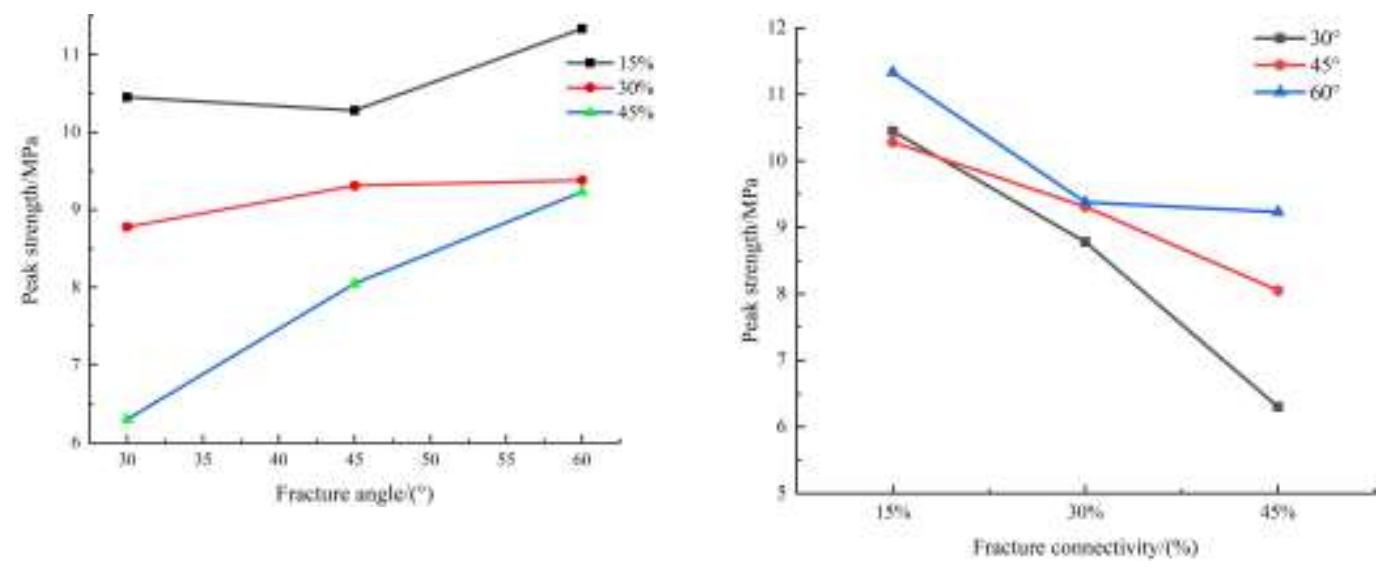

Fig. 8 Effect of fracture angle and connectivity on the peak sample strength

The peak strength of the soft rock-like specimens with different fracture angle and connectivity values are normalized according to $f_{c u}^{\prime \prime}=f_{c u}^{\prime} / f_{c u}$, as shown in Table 4, and fitted using MATLAB software (Fig. 9). The fracture angle and connectivity show a significant impact on the peak strength of soft rock, 
and the fitting result is approximately planar.

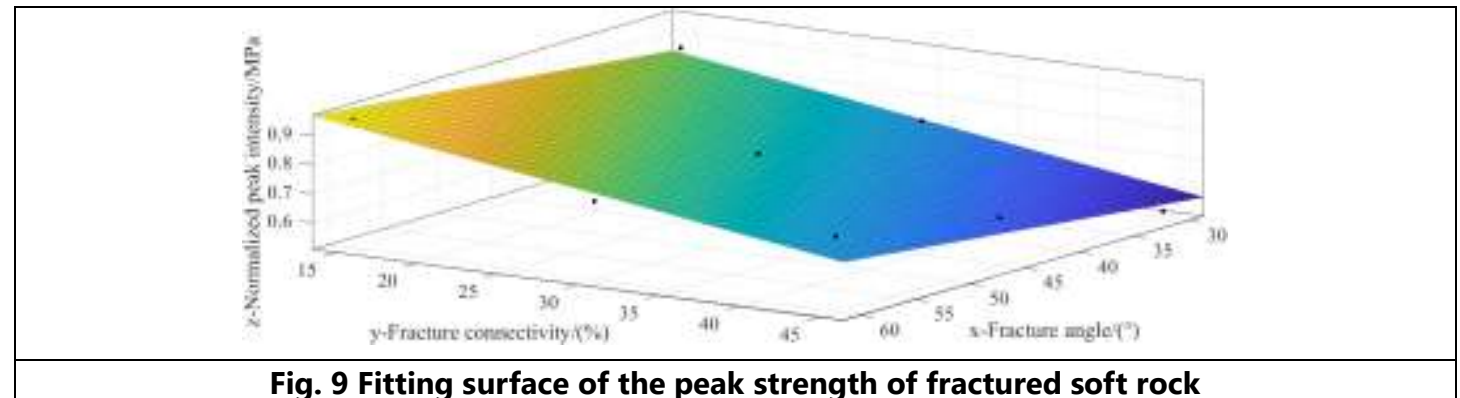

Fig. 9 Fitting surface of the peak strength of fractured soft rock

The polynomial (Eq. 2) of the strength reduction coefficient of fractured soft rock-like material $(\alpha)$ is obtained with respect to the fracture angle ( $x$ in degrees) and fracture connectivity ( $y$ in \%) according to the linear regression analysis of the fitted plane. The peak strength of fractured soft rock-like material $\left(f_{c u}^{\prime}\right)$ can be further calculated with respect to $x$ and $y$ according to that of intact soft rock-like material (Eq. 3) as follows:

$$
\begin{gathered}
\alpha=\left\{\begin{array}{cl}
1, & y=0 \\
0.8228+0.00411 x-0.00789 y & ,\left\{\begin{array}{l}
\mathrm{y}=15 \sim 45 \\
x=30 \sim 60
\end{array}\right.
\end{array} \quad R^{2}=0.95\right. \\
f_{c u}^{\prime}=f_{c u} \cdot \alpha
\end{gathered}
$$

For an intact soft rock-like material $(y=0), \alpha=1$. When the specimen is fractured soft rock-like material $(y>0)$, the $\alpha$ and $f_{c u}^{\prime}$ values can be calculated according to Eq. (3). The calculated $\alpha$ and peak strength values of fractured soft rock-like material can be obtained by substituting $x\left(30^{\circ}, 45^{\circ}, 60^{\circ}\right)$ and $y(15 \%$, $30 \%, 45 \%$ ) into Eq. (2) and Eq. (3) (Table 6). The minimum absolute value of the difference between the test and calculated values of fractured soft rock-like material is $0.03 \mathrm{MPa}$, the maximum is $0.76 \mathrm{MPa}$, and the average value is 0.4 $\mathrm{MPa}$. The difference of the absolute values is less than $1 \mathrm{MPa}$. The peak strength 
of fractured soft rock-like material can therefore be calculated according to Eq. (2) and Eq. (3).

Table 6 Calculated peak strength of fractured soft rock

\begin{tabular}{|c|c|c|c|c|c|c|c|c|c|}
\hline angle & & $30^{\circ}$ & & & $45^{\circ}$ & & & $60^{\circ}$ & \\
\hline connectivity & $15 \%$ & $30 \%$ & $45 \%$ & $15 \%$ & $30 \%$ & $45 \%$ & $15 \%$ & $30 \%$ & $45 \%$ \\
\hline test value & 10.45 & 8.78 & 6.3 & 10.28 & 9.31 & 8.05 & 11.33 & 9.38 & 9.23 \\
\hline $\begin{array}{l}\text { calculated } \\
\text { value } \\
\text { absolute }\end{array}$ & 9.90 & 8.48 & 7.06 & 10.63 & 9.21 & 7.80 & 11.36 & 9.95 & 8.54 \\
\hline $\begin{array}{l}\text { values of } \\
\text { difference }\end{array}$ & 0.55 & 0.3 & 0.76 & 0.35 & 0.1 & 0.25 & 0.03 & 0.57 & 0.69 \\
\hline
\end{tabular}

\subsubsection{Effect of fractures on the failure mode}

Previous studies have shown that there are four fracture penetration modes during the propagation process of fractured rock: tensile mode, shear mode, compressive mode, and mixed mode $\mathrm{e}^{30}$. The stress exerted on the specimen gradually increases with increasing load, but the proportion of anisotropic stress at one point changes continuously owing to the nonlinearity of the soft rocklike material and development of internal damage. The specimen is compressed in the vertical direction and expands (i.e., elongates) in the horizontal direction. Fractures appear inside the soft rock-like specimen when the horizontal elongation strain of the specimen exceeds the ultimate tensile stress.

For the intact soft rock-like specimen under uniaxial compression, the main fracture develops vertically along the upper and lower ends of the oblique direction along the height center of the specimen, and then turns to the corner of the specimen at the loading surface to form a "八" shape that is vertically and 
inversely connected, as shown in Fig. 10.
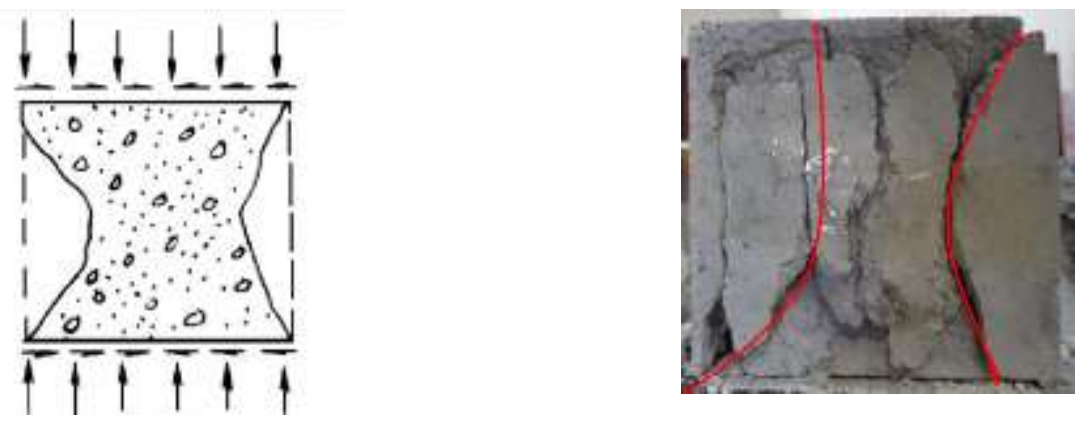

Fig. 10 Destruction image of the intact specimen

Because the failure mode of the fractured soft rock-like specimen is affected by the fracture angle and connectivity, the fractures generated under uniaxial compression extend along the principal stress direction or bend along the prefabricated fracture tip. The secondary fractures leading to the deformation and failure of the fractured soft rock-like specimen therefore mainly include wing fracture and secondary coplanar fractures (Fig. 11).

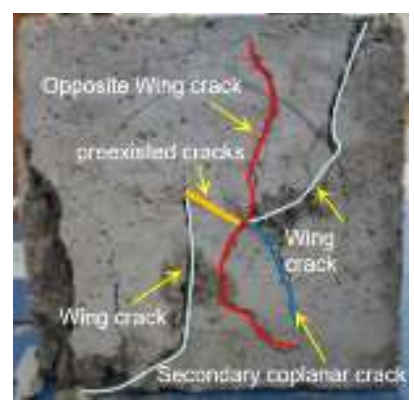

Fig. 11 Fracture classification of the soft rock-like specimen

The failure modes of the fractured soft rock-like specimens mainly include tensile failure, shear failure, and mixed failure. As shown in Fig. 12a, a new fracture began to develop from the fracture tip and produced secondary fractures in the $30^{\circ}$ fracture specimen. When the fracture connectivity was $15 \%$ or $30 \%$, the specimen produced two main fractures along the principal stress 
direction. When the fracture connectivity was $45 \%$, the soft rock-like specimen produced tensile wing fractures, which rapidly developed through the top and bottom of the specimen. This led to specimen failure and a reduction of the bearing capacity, and its failure form was mainly tensile failure.

The failure of the specimen with a $45^{\circ}$ fracture angle under uniaxial compression notably differed from that of the specimen with a $30^{\circ}$ fracture angle. As shown in Fig. 12b, during loading, the fracture developed along the $45^{\circ}$ prefabricated fracture to penetrate the entire fracture surface, and the fracture connectivity exerted a large impact on the failure mode. When the fracture connectivity was $15 \%$, the specimen produced two wing fractures along the principal stress direction, and the main failure mode was tensile failure. When the fracture connectivity was 30\%, the macro-fracturing occurred as wing fractures and secondary coplanar fractures, which reflects a mixture of tensile and shear failure with $45 \%$ of the tensile fractures on both sides of the fractured soft rock-like material running through the entire specimen. The failure mode was therefore mainly shear failure and supplemented by tensile failure.

In Fig. 12 c, the specimen with a $60^{\circ}$ fracture is shown to be relatively broken as a whole. During the loading process, shear sliding fractures appeared at the fracture tip. The fracture surface of the specimen with $15 \%$ fracture connectivity appeared as a " $Y$ " shape, and its failure mode was mainly shear failure. The crushing degree of the specimen with $30 \%$ fracture connectivity was relatively high, and the fracture trace deflections and section concave convex fluctuations 
were caused by heterogeneity of the specimen material. Two tensile wing fractures occurred through the top and bottom of the specimen with $45 \%$ fracture connectivity and formed a shear plane along the prefabricated fracture, indicating a mixed failure mode of tension and shear failure.
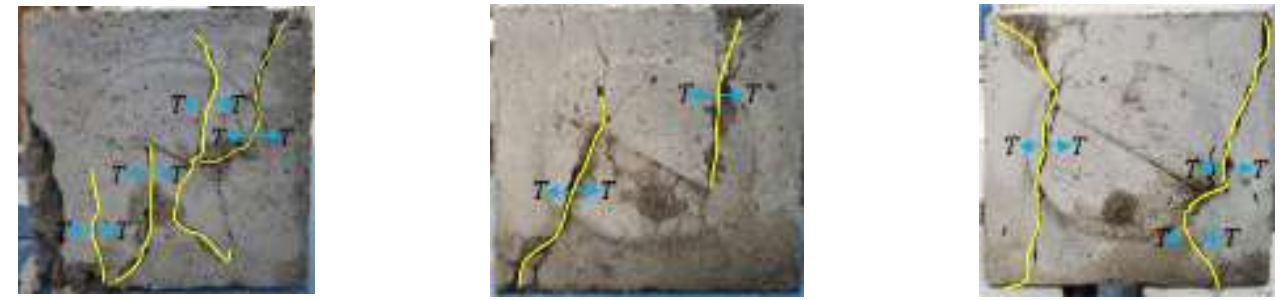

(a) Failure image of the $30^{\circ}$ fractured soft rock-like specimen
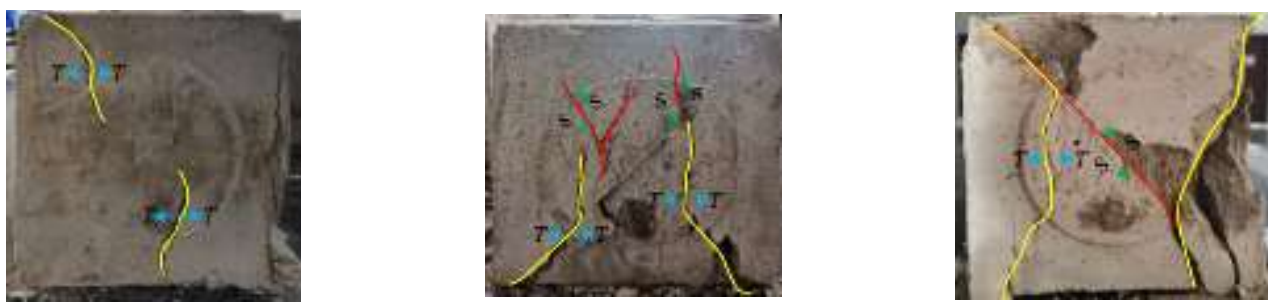

(b) Failure image of the $45^{\circ}$ fractured soft rock-like specimen
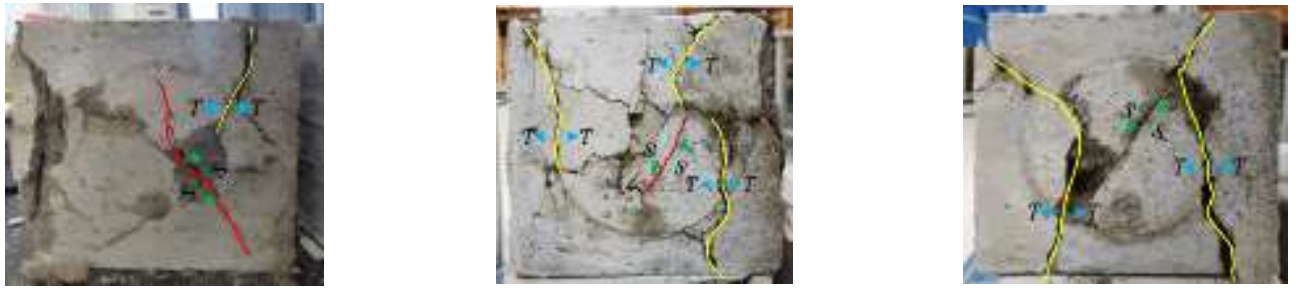

(c) Failure image of the $60^{\circ}$ fractured soft rock-like specimen

Fig. 12 Failure images of the fractured rock specimens under uniaxial compression

In summary, the secondary fractures caused by the deformation and failure of the fractured soft rock-like specimens under uniaxial compression mainly included wing fractures and secondary coplanar fractures. The failure mode was significantly affected by the fracture angle and connectivity. The specimen with a $30^{\circ}$ fracture angle mainly underwent tensile failure, whereas the specimens with $45^{\circ}$ and $60^{\circ}$ angle mainly underwent shear failure when the connectivity was high (45\%). The evolution of the fracture generation and propagation can be further analyzed in combination with the AE characteristics during the failure 
process. The destruction process of fractured soft rock-like material can therefore be fully understood according to the $A E$ characteristics and failure mode under uniaxial compression.

\section{Discussion}

Rock mass contains a large number of defects (e.g., fractures and faults), which are closely related to its deformation and failure behavior. Different numbers of fractures, occurrences, and scales therefore influence the rock deformation and failure characteristics.

In this paper, uniaxial compression tests were performed on soft rock-like simulation materials with prefabricated fractures to systematically study the effects of fracture angle and connectivity on the strength and deformation characteristics of soft rock. The results reflect the following aspects.

(1) Effect of fractures on the stress-strain curve and acoustic emission characteristics.

The characteristic points of the stress-strain curve of fractured soft rocklike specimens, namely elastic starting point $A$, elastic limit point $B$, and internal fracture development point $C$ (Table 7 ), are studied relative to the intact soft rock-like specimen (Eq. (1)).

Table 7 Analysis of characteristic points of the soft rock-like specimens

\begin{tabular}{cccc}
\hline characteristic points & A & B & C \\
\hline Intact specimen & 0.36 & 0.68 & 0.96 \\
Fracture angle of $30^{\circ}$ and $15 \%$ fracture connectivity & 0.36 & 0.69 & 0.94 \\
Fracture angle of $30^{\circ}$ and 30\% fracture connectivity & 0.38 & 0.71 & 0.94 \\
$24 / 32$ & & &
\end{tabular}




\begin{tabular}{llll} 
Fracture angle of $30^{\circ}$ and $45 \%$ fracture connectivity & 0.37 & 0.69 & 0.96 \\
Fracture angle of $45^{\circ}$ and $15 \%$ fracture connectivity & 0.38 & 0.70 & 0.92 \\
Fracture angle of $45^{\circ}$ and $30 \%$ fracture connectivity & 0.36 & 0.72 & 0.97 \\
Fracture angle of $45^{\circ}$ and $45 \%$ fracture connectivity & 0.35 & 0.72 & 0.94 \\
Fracture angle of $60^{\circ}$ and $15 \%$ fracture connectivity & 0.34 & 0.72 & 0.95 \\
Fracture angle of $60^{\circ}$ and $30 \%$ fracture connectivity & 0.33 & 0.68 & 0.96 \\
Fracture angle of $60^{\circ}$ and $45 \%$ fracture connectivity & 0.34 & 0.62 & 0.92 \\
\hline
\end{tabular}

The values in Table 7 show that the differences between the characteristic points of the fractured and intact soft rock-like specimens are less than 0.1 . This method can therefore be used to determine the location of the characteristic points of fractured soft rock-like material and further divide its stress-strain curve into four stages: compaction stage $(O A)$, elastic deformation stage (AB), stable fracture development stage $(\mathrm{BC})$, and unstable fracture development stage (CD). The stress-strain curves of fractured and intact soft rock-like material therefore undergo similar deformation stages. The stress-strain curves of the fractured soft rock-like material fluctuate before the peak, drop stepwise after the peak, and rise after the peak owing to the fracture differences.

The AE energy signal of soft rock-like material shows clear phases and is highly consistent with the stress-strain curve, and thus can well reflect the failure characteristics and deformation mechanism of fractured soft rock-like material under uniaxial compression. AE technology therefore has important theoretical significance and provides important reference values for monitoring the effects of soft rock-like material deformation.

(2) Effect of fractures on the failure mode.

The specimen with a fracture angle of $30^{\circ}$ mainly underwent tensile failure 
under uniaxial compression, whereas the specimens with $45^{\circ}$ and $60^{\circ}$ angle mainly underwent shear failure under high connectivity (45\%).

(3) Effect of fractures on the peak strength.

When the fracture connectivity is constant, the peak strength of fractured soft rock-like material basically increases with the increase of fracture angle; when the fracture angle is constant, the peak strength of fractured soft rock specimens decreases with the increase of fracture connectivity. But the damage degree of the fractured soft rock specimens with a high angle and high connectivity was less affected by fractures.

The peak strain corresponding to the strength of the soft rock-like specimens can reflect the soft rock-like material deformation characteristics. Under uniaxial compression, the average peak strain of intact soft rock-like material was $1.0 \times 10^{-2}$, whereas the fractured soft rock-like material showed higher peak strain values to varying degrees (Table 8 ). The maximum peak strain was $2.07 \times 10^{-2}$ for the specimen with a $30^{\circ}$ fracture angle and $45 \%$ fracture connectivity. The minimum peak strain was $1.17 \times 10^{-2}$ for the specimens with a $60^{\circ}$ fracture angle and $15 \%$ fracture connectivity.

Table 8 Peak strain of the fractured soft rock: $\varepsilon / 10^{-2}$

\begin{tabular}{ccccc}
\hline & Fracture angle & $30^{\circ}$ & $45^{\circ}$ & $60^{\circ}$ \\
\hline Fracture connectivity & & & \\
\hline $15 \%$ & 1.50 & 1.30 & 1.17 \\
$30 \%$ & 1.84 & 1.54 & 1.20 \\
$45 \%$ & 2.07 & 1.59 & 1.27 \\
\hline
\end{tabular}

This demonstrates that different variation rules occur owing the influence of fracture angle and connectivity (Fig.13). When the fracture connectivity is 
held constant, the peak strain decreases with increasing fracture angle. When the fracture angle is held constant, the peak strain increases with increasing fracture connectivity.

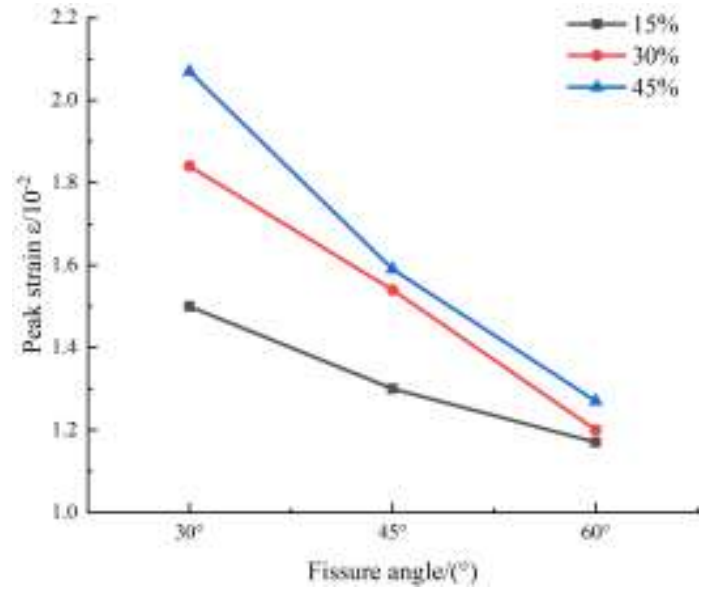

(a) Effect of fracture angle on the peak strain of soft rock-like specimens

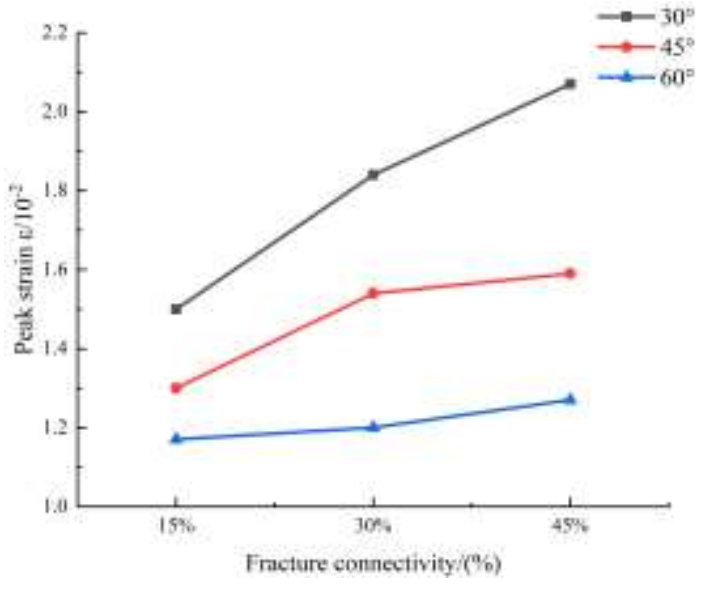

(b) Effect of fracture connectivity on peak strain of soft rock-like specimens

Figure 13 Effect of fracture angle and connectivity on the peak strain of soft rock 


\section{Summary}

In this paper, cement-based materials are used to simulate soft rock, and the influence laws and acoustic emission characteristics of preset fracture angle and connectivity on uniaxial stress-strain behavior of soft rock-like material are studied. The main conclusions are summarized as follows:

(1) Compared with the intact soft rock-like material, the stress-strain curve of fractured soft rock-like material shows similar stages as intact soft rock-like material, while the post-peak failure stage is different due to the influence of the fracture; The peak strength of fractured soft rock-like material is lower than that of intact soft rock-like material, and it decreases with the decrease of the fracture angle and the increase of the connectivity; The relationship between the strength reduction coefficient $(\alpha)$ of soft rock-like material, and fracture angle (x) and fracture connectivity $(y)$ can be described as $\alpha=$ $0.8228+0.00411 x-0.00789 y$.

(2) Under uniaxial compression, the intact soft rock-like specimen formed an “八" shape that connects positively and inversely. The failure mode of the fractured soft rock-like specimens was significantly affected by the fracture angle and connectivity. The secondary fractures that formed during deformation and failure mainly included wing fractures and secondary coplanar fractures. The specimen with a $30^{\circ}$ fracture angle mainly underwent tensile failure under loading, whereas the specimens with $45^{\circ}$ and $60^{\circ}$ fracture angle mainly underwent shear failure under the condition of high 
connectivity (45\%).

(3) The results show that $A E$ data can reflect the internal energy release process of soft rock, and the entire process of micro-growth, aggregation, and penetration until failure under uniaxial compression. The AE characteristics of soft rock-like material are highly consistent with the stress-strain curve.

\section{Acknowledgments}

This study was supported by the National Key Research and Development Program (Grant No. 2019YFC1509704) and the National Natural Science Foundation of China (Grant No. U1704243). We thank Esther Posner, PhD, from Liwen Bianji, Edanz Editing China (www.liwenbianji.cn) for editing the English text of a draft of this manuscript.

\section{Declarations}

Funding: National Key Research and Development Program (Grant No. 2019YFC1509704); National Natural Science Foundation of China (Grant No. U1704243)

Conflicts of interest: The authors declare they have no financial interests.

Availability of data and material: All data and materials support our published claims and comply with field standards.

Code availability: All software application or custom code support our published claims and comply with field standards.

Authors' contributions: All authors contributed to the study conception and design. Material preparation, data collection and analysis were performed by Jingjing Liu and Shiying Zhang. The first draft of the manuscript was written by Jingjing Liu and all authors commented on previous versions of the manuscript. All authors read and approved the final manuscript.

Consent for publication: We Han-Dong Liu, Jing-Jing Liu, Shi-Ying Zhang, Ling-Yun Feng, Lei Qiu give our consent for information about ourselves (circle as appropriate) to be published in International Journal of Concrete Structures and Materials (IJCSM). We understand that the information will be published without our (circle as appropriate) name attached, but that full anonymity cannot be guaranteed. We understand that the text and 
any pictures or videos published in the article will be freely available on the internet and may be seen by the general public. The pictures, videos and text may also appear on other websites or in print, may be translated into other languages or used for commercial purposes. We have been offered the opportunity to read the manuscript.

\section{Authors' information}

Handong Liu, Professor, Henan Key Laboratory of Geomechanics and Structural Engineering, North China University of Water Resources and Electric Power, Zhengzhou, 450045, China (Han-Dong Liu's E-mail: Liuhandong@ncwu.edu.cn)

Shiying Zhang, Assistant Professor, Power China HuaDong Engineering Corporation Limited, Hangzhou, Zhejiang 311122, China (Shi-Ying Zhang's E-mail: 1908299746@qq.com)

Lingyun Feng, Ph.D. Student, College of Geosciences and Engineering, North China University of Water Resources and Electric Power, Zhengzhou 450046, China (Ling-Yun Feng's E-mail:405759200@qq.com)

Lei Qiu, Assistant Professor, Power China HuaDong Engineering Corporation Limited, Hangzhou, Zhejiang 311122, China (Lei Qiu's E-mail: 957977971@qq.com)

\section{Reference}

1.Cao P, Liu T, Pu C, Lin H. Crack propagation and coalescence of brittle rock-like specimens with pre-existing cracks in compression. Engineering Geology. 2015;187:113-121.

2.Wasantha P, Bing D, Yang SQ, Xu T. Numerical modelling of the crack-pore interaction and damage evolution behaviour of rocklike materials with pre-existing cracks and pores. International Journal of Damage Mechanics. 2020:105678952098387.

3.Wawersik WR, Fairhurst C. A study of brittle rock fracture in laboratory compression experiments. International Journal of Rock Mechanics \& Mining Sciences \& Geomechanics Abstracts. 1970;7(5):561,IN567,565-564,IN514,575.

4.Chen X, Li D, Wang L, Zhang S. Experimental study on effect of spacing and inclination angle of joints on strength and deformation properties of rock masses under uniaxial compression. Chinese Journal of Geotechnical Engineering. 2014;36(12).

5.Hu Z. Anisotropy and strength characteristics of jointed rock mass, Beijing Jiaotong $30 / 32$ 
University 2015.

6.Wang Z, Xiong L. Uniaxial compression test and numerical simulation of fractured rock mass with single joint. Geological hazards and environmental protection. 2019(2):5.

7.Yin Y, Li G, Liu Y, Jiang X, Luan W. Research on uniaxial compression of jointed rock mass based on numerical simulation. IOP Conference Series: Earth and Environmental Science. 2021;804(2):022053 (022055pp).

8.Zhu W, Chen W. Study on model test and fracture mechanics mechanism of wild goose crack propagation. Journal of Solid Mechanics. 1998;019(004):355-360.

9. Liu T, Lin T. Soft rock engineering design theory and construction practice: Beijing: China Architecture and Building Press, 2001.; 2001.

10. Li HB, Li JR, Zhou QC, Liu YQ, Xia X. Study on the mechanical properties of soft rock under dynamic uniaxial compression. Key Engineering Materials. 2004;261/263(Part 1): p.277-281.

11. P. M, G. V. Estimation of embankment settlement caused by deterioration of soft rock grains. Bulletin of Engineering Geology and the Environment. 2017.

12. Wang y, Ai Q, Wang W, Li JL. Study on uniaxial compressive strength characteristics and transfixion mechanism of soft rock with non-transfixion fractures. Water Resources and Hydropower Engineering. 2018(4):154-161.

13. Fan QZ, Gao YF. Study on nonlinear creep model of soft rock. Chinese Journal of Geotechnical Engineering. 2007;29(004):505-509.

14. Manthei G, Eisenbltter J. Acoustic emission in study of rock stability: Springer Berlin Heidelberg; 2008.

15. He MC, Miao JL, Feng JL. Rock burst process of limestone and its acoustic emission characteristics under true-triaxial unloading conditions. International Journal of Rock Mechanics and Mining Sciences. 2010;47(2):286-298.

16. Li S, Yin X, Wang Y, Fang H. Studies on acoustic emission characteristics of uniaxial compressive rock failure. Chinese Journal of Rock Mechanics and Engineering. 2004;23(15):2499-2503.

17. Moradian Z, Einstein HH, Ballivy G. Detection of cracking levels in brittle rocks by parametric analysis of the acoustic emission signals. Rock Mechanics \& Rock Engineering. 2016;49(3):785-800.

18. $\operatorname{Vr} \mathrm{A}, \mathrm{JV} \mathrm{A}, \mathrm{TI} \mathrm{B}$. Laboratory studies of acoustic emission prior to uniaxial compressive rock failure. International Journal of Rock Mechanics and Mining Sciences. 2000;37(4):699704.

19. Browning J, Meredith PG, Stuart CE, Healy D, Harland S, Mitchell TM. Acoustic characterization of crack damage evolution in sandstone deformed under conventional and true triaxial loading. Journal of Geophysical Research: Solid Earth. 2017;122(6).

20. Tang C, Liu S, Yang K. Asymmetric failure mechanism and control of downhill roadway group of soft rock in deep mine. Journal of Mining \& Safety Engineering. 2019(3).

21. Hunt, Roye. Geotechnical engineering analysis and evaluation [M]. Geotechnical engineering analysis and evaluation, 1986.

22. Liu HN, Wang JM, Wang SJ. Experimental research of columnar jointed basalt with true triaxial apparatus at Baihetan Hydropower Station. Rock and Soil Mechanics. 2010;031(00z):163-171. 
23.Fan QZ, Gao TF. Study on Creep Properties and Nonlinear Creep Model of Soft Rock[J]. Chinese Journal of Rock Mechanics and Engineering, 2007.

24. Li F, Yang J, Liu W, et al. Effect of loading rate changing on the mechanical properties of mudstone under uniaxial compression [J]. Rock and Soil Mechanics 2021, 42(2): 10.

25. Zhou YH, Zhou DP, Yang T, et al. Testingl Study on the Mechanical Property of Several Soft Rocks of red Bed; proceedings of the Conference of Chinese Society of Rock Mechanics and Engineering, F, 2004 [C].

26. Zhu YM, Chen L, Zhang H, et al. Physical and Mechanical Characteristics of Soft Rock Tunnel and the Effect of Excavation on Supporting Structure [J]. Applied Sciences, 2019, 9(8).

27. Chen JL, Zhou WJ, Niu W, et al. 《Sand for construction》(GB/T14684-2011) revision explanation [J]. Architecture Technology, 2012, 43(007): 591-4.

28. Guo Z. Strength and deformation test foundation and constitutive relationship of concrete: Strength and deformation test foundation and constitutive relationship of concrete; 1997.

29. Yong L, Hao Z, Zhu W, Li S, Tong L. A creep constitutive model considering geometric damage of fractured rock mass and its application. Paper presented at: the 49th US Rock Mechanics / Geomechanics Symposium held in , 28 June- 1 July 2015, 2015.

30. Tang C, Huang K, Lin P, Zhou J. Mechanisms of crack coalescence of prexisting flaws unded biaxial compression. Chinese Journal of Rock Mechanics and Engineering. 2002;21(006):808-816. 